\title{
Analysis of computational fluid dynamics (CFD) on fiber reinforced self-compacting concrete
}

\author{
Anbalagan $\mathbf{C}^{\mathbf{1}^{*}}$, Thenmozhi $\mathbf{S}^{\mathbf{2}}$, Gowri $\mathbf{V}^{\mathbf{3}}$, Banupriya $\mathrm{S}^{\mathbf{4}}$ \\ ${ }^{1}$ Department of Civil Engineering, Bharath Institute of Higher Education and Research, \\ Chennai, Tamil Nadu, India \\ ${ }^{23}$ Department of Civil Engineering, St.Joseph's Institute of Technology, Chennai, Tamil \\ Nadu, India \\ ${ }^{4}$ Department of Civil Engineering, St.Joseph's College of Engineering, Chennai, Tamil Nadu, \\ India \\ *Corresponding author: anbalagan.civil @bharathuniv.ac.in
}

\begin{abstract}
An experimental and CFD analysis of self-compacting concrete uses quarry dust and various partial flea ash substitutes, silica fumes, and both flea ash and silica fume combinations to construct a finely-structured polypropylene reinforced concrete beam. Using three different fractions of fiber volume, this article investigates the influence of polypropylene fibers on self-compacting concrete beams (2.0 percent, 2.5 percent and 3.0 percent). The M30 grade was taken into consideration. This study employed a computational fluid dynamics tool to model the experimental beam and failure scenarios. The three-dimensional CFD technique method used to model concrete beams has proven to be a reliable predictive tool for concrete beam analysis. However, when performing non-linear CFD analysis, it is critical to select appropriate finite elements and the correct mesh density in order to obtain a satisfactory solution to the problem. Furthermore, it has been discovered that linear regression may provide a good forecast of first crack load, deflection at first crack load, yield load, deflection at yield load, ultimate load, deflection at ultimate load, and ultimate load, deflection at ultimate load. There is a high level of agreement between the forecast and the test findings.
\end{abstract}

Keywords: CFD Analysis, Concrete, Fiber, Beam, Mechanical Strength

\section{Introduction}

Quarry dust has been utilised in the construction industry for a variety of purposes, including road construction and the production of lightweight aggregates, bricks, tiles, and autoclave blocks [1]. For the past three decades, finely qualified quarry dust has been recognised as a construction material in Western countries [2]. Quarry dust was initially used in concrete as a fine aggregate replacement for sand. The workability of concrete was found to be harmed by quarry dust. Quarry dust, on the other hand, has increased the mechanical and long-term performance of concrete. For the past three decades, several attempts have been made to evaluate the potential of quarry dust as a fine aggregate and its impact on the characteristics of both fresh and cured concrete. 
It is a by-product of stone crushers that is abundant and inexpensive in many regions. It is commonly seen as a waste product, which creates a disposal issue. If it is used as fine aggregate in concrete, it will undoubtedly help to solve environmental issues. [3] Inclusion of quarry dust will pay for the cost of concrete production, and so the efficient use of quarry dust as fine aggregate will turn this waste item into a useful resource. [4].

Furthermore, with adequate quarry dust treatment before to use, attempts have been made to totally substitute sand in concrete. Because of decreased permeabilities and increased density, stem dust as a finely aggregated concrete gives greater resilience and strength [5]. The strength and durability of quarry dust concrete is found to be nearly $10 \%$ higher than normal concrete [6].

SCC performance was investigated using different percentages of polypropylene fibres. The fresh and hardened properties of fibre reinforced self-compacting concrete containing fly ash have been investigated. It was determined that 0.01 percent polypropylene fibre meets EFNARC criteria and produces better results than other trial mixtures [7].

Furthermore, attempts have been made to research the characteristics of SCC and the suitability of various fly ash, silica fume, and quarry dust alternatives for use in SCC. The compressive strength and tensile strength division of SCC with various partial cement replacements by Fly Ash and Silica Fume reveals optimum compressive strength and break strength [8]. Finally, the results of replacing 100 percent of the river sand with quarry dust show that the compression and break tensile strength improves when compared to river sand. Without reinforcement, I attempted to investigate the flexural strength of self-compacting concrete using polypropylene fibres and fly ash. Polypropylene fibres have been found to boost the overall strength of concrete in both compressive and flexural strength when used in the hardened condition. Flexural strength increases by 21.30 percent without reinforcement compared to standard concrete [9].

In order to identify fibre combinations that provide optimum synergy, the author conducted a research of the potential for fibre refinement on hybrid fibre reinforced concrete [10]. The compression strength, fracture modulus, and bending hardness of hybrid fibre reinforced concrete were investigated in this work. Synergy has been found in hybridizations based on macro steel fibres and micro polypropylene fibres. With hybridised polypropylene crimped macrofibers and carbon and polypropylene microfibers, there was complete synergy[11].

The behaviour of reinforced concrete beams under fatigue loading was investigated. It was discovered that cyclic loading increased the measured steel strain at flexural crack sites. In addition, due to an evident increase in deflection that accompanied concrete softening, the flexural stiffness of the beams was somewhat reduced [13].

The flexural behaviour of hybrid cement composites was investigated. By volume, the polyolefin and steel fibre content ranged from 0 to $2 \%$. In addition, the total hybrid fibre content was changed between 1 and 2 percent by volume. Four-point bending was used to test 
the flexural specimens. The flexural performance of FRC was greatly improved when concrete with $2 \%$ hybrid fibre content was used [14].

The structural performance in terms of cracking behaviour, ductility, and energy absorption was tested experimentally, and the results were found to be consistent with the analytical results. It has been found that fibre reinforced concrete beams outperformed conventional reinforced concrete beams made with various amounts of fly ash and silica fume in SCC mixes. The results revealed that SCC with $15 \%$ silica fume had a higher compressive strength than those containing $30 \%$ fly ash. In addition, SCC with $10 \%$ fly ash and $10 \%$ silica fume had a greater compressive strength [17].

However, the structural performance of self-compacting fiber reinforced concrete has yet to be investigated when river sand is completely replaced with quarry dust. As a result, a study of the effect of quarry dust on the structural performance of self-compacting fiber reinforced concrete has been undertaken. To investigate the features of polypropylene fiber reinforced self-compacting concrete, such as filling ability, passage ability, and segregation resistance, in fresh self-compacting concrete.

\section{METHODS AND MATERIALS}

Nine rectangular reinforced concrete beams with a cross section of 200X250 mm and a length of $2500 \mathrm{~mm}$ were cast and evaluated for SCC structural performance. Four of the nine beams were formed entirely of river sand as fine aggregate (SCC-RS), while the other four were made entirely of quarry dust. One beam represents SCC-RS without mineral admixture, the second beam represents SCC with 10\% fly ash, and the third beam represents SCC with 15\% silica fume. Fiber reinforced SCC-RS with ternary blend is shown by the fourth beam (15 percent $\mathrm{SF}$ and 10 percent FA). from figure 1 Four further beams were manufactured using the SCC - QD combination. In addition, one typical RCC beam was produced and used as a control beam.

The flexural behaviour of SCRC beams, SCFRC beams, and Conventional Control Mix (CCB) beams is explored experimentally. The first crack load, deflection at first crack load, yield load, deflection at yield load, ultimate load, deflection at ultimate load are among the experimental investigations. Table 1 shows the results of determining these parameters using RC simply supported beams with a two point loading method.

Table 1. Load and deflection of SCC- QD and SCC-RS blended as fine aggregates

\begin{tabular}{|l|c|l|c|c|c|c|}
\hline $\begin{array}{c}\text { Mix } \\
\text { code }\end{array}$ & $\begin{array}{c}\text { Load } \\
\text { at first } \\
\text { crack } \\
(\mathbf{k N})\end{array}$ & $\begin{array}{l}\text { Deflection at } \\
\text { first crack } \\
\text { load(mm) }\end{array}$ & $\begin{array}{c}\text { Yield } \\
\text { load } \\
(\mathbf{k N})\end{array}$ & $\begin{array}{c}\text { Deflection at } \\
\text { yield load } \\
(\mathbf{m m})\end{array}$ & $\begin{array}{c}\text { Ultimate } \\
\text { load (kN) }\end{array}$ & $\begin{array}{c}\text { Deflection at } \\
\text { ultimate } \\
\text { load(mm) }\end{array}$ \\
\hline C-CB & 4.4 & 0.3 & 23.3 & 1.08 & 89.42 & 7.24 \\
\hline RS & 5.2 & 0.6 & 25.4 & 1.30 & 115.4 & 9.54 \\
\hline QD & 6.3 & 0.57 & 27.3 & 1.63 & 152.4 & 12.87 \\
\hline
\end{tabular}




\begin{tabular}{|l|c|c|c|c|c|c|}
$\begin{array}{l}\text { RS- } \\
\text { SF15 }\end{array}$ & 7.2 & 0.58 & 29.40 & 1.74 & 101.3 & 18.7 \\
\hline $\begin{array}{l}\text { QD- } \\
\text { SF15 }\end{array}$ & 9.4 & 0.71 & 32.6 & 2.42 & 125.4 & 20.41 \\
\hline $\begin{array}{l}\text { RS- } \\
\text { FA10 }\end{array}$ & 6.2 & 0.59 & 26.4 & 1.62 & 137.33 & 12.74 \\
\hline $\begin{array}{l}\text { QD- } \\
\text { FA10 }\end{array}$ & 7.4 & 0.50 & 26.3 & 1.55 & 152.44 & 15.62 \\
\hline $\begin{array}{l}\text { RS- } \\
\text { FA10- } \\
\text { SF15- } \\
\text { PPF }\end{array}$ & 7.3 & 0.62 & 30.41 & 1.58 & 183.48 & 15.62 \\
\hline $\begin{array}{l}\text { QD- } \\
\text { FA10- } \\
\text { SF15- } \\
\text { PPF }\end{array}$ & 8.2 & 0.74 & 33.2 & 1.74 & 208.42 & 14.62 \\
\hline
\end{tabular}

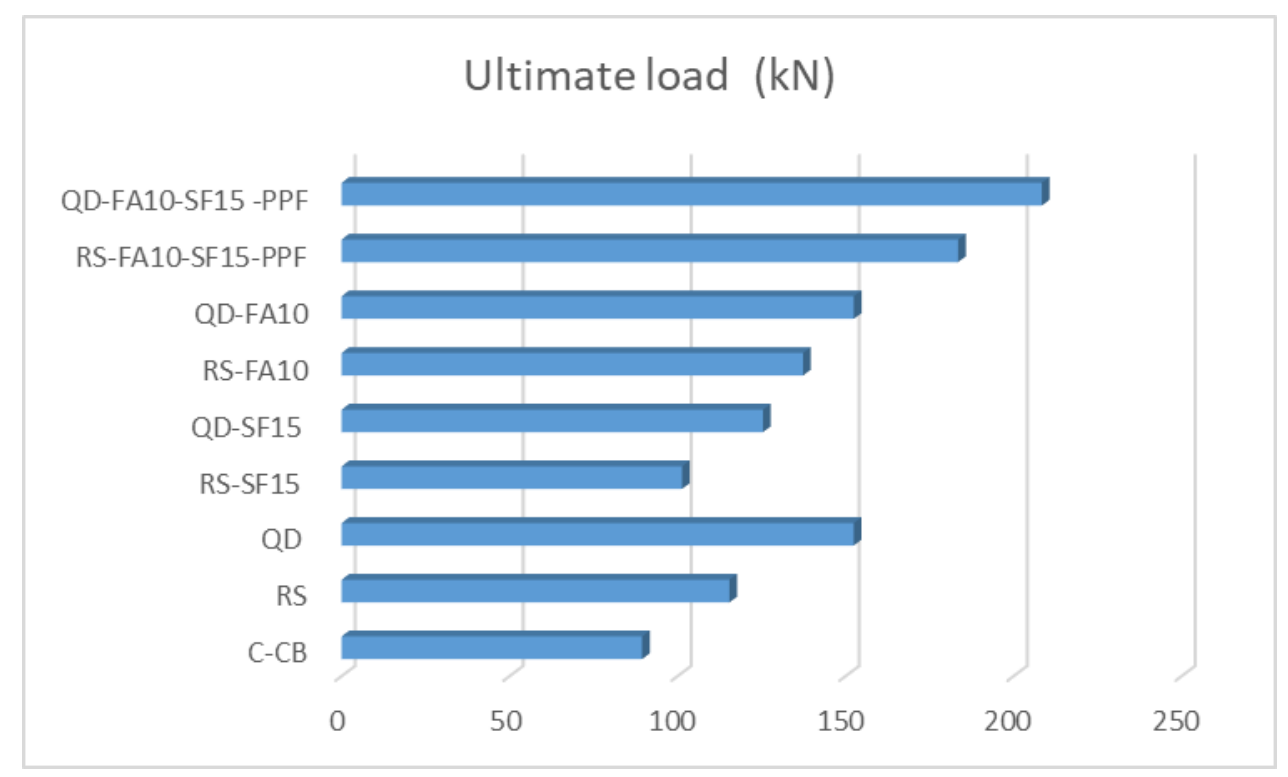

Figure 1. SCC beams have a higher load at first crack than C-CB beams by a percentage.

Figure 1 depicts the influence of self-compaction, quarry dust, and polypropylene fibres on R.C beam deflection at first crack stress. The fact that all of the SCC beams displayed significantly larger deflection at first crack load than the C-CB beams is obvious. In addition, beams built with the QD-SF15 mix had the largest deflection at first crack load than beams made with other mixes. It's around 73.68 percent higher than the usual control mix beam. Furthermore, except for the beam representing the QDFA10 mix, beams made with SCC - QD mixes showed larger deflection at first crack stress than SCC-RS mixes. Furthermore, beams made with SCC-SF binary mixes had significantly larger deflection at first fracture than beams made with SCC-FA binary mixes. 
The effect of Self compaction, quarry dust and polypropylene fibers on yield load of R.C beams is shown in Fig 2. The Fig. shows that beams made with QD-SF15 mix has exhibited highest yield load than other mixes. It is about $71.79 \%$ higher than the beams representing conventional control mix. Also, all the SCC beams exhibited relatively higher yield load than beams made with C-CB. Further, beams made with SCC - QD mixes have shown relatively higher yield load than SCC-RS mixes. Moreover, the SCC-SF binary mixes have exhibited remarkably higher yield load than SCC-FA mixes. The incorporation of PPF in SCC beams has not made any significant improvement in yield load of SCC beams.

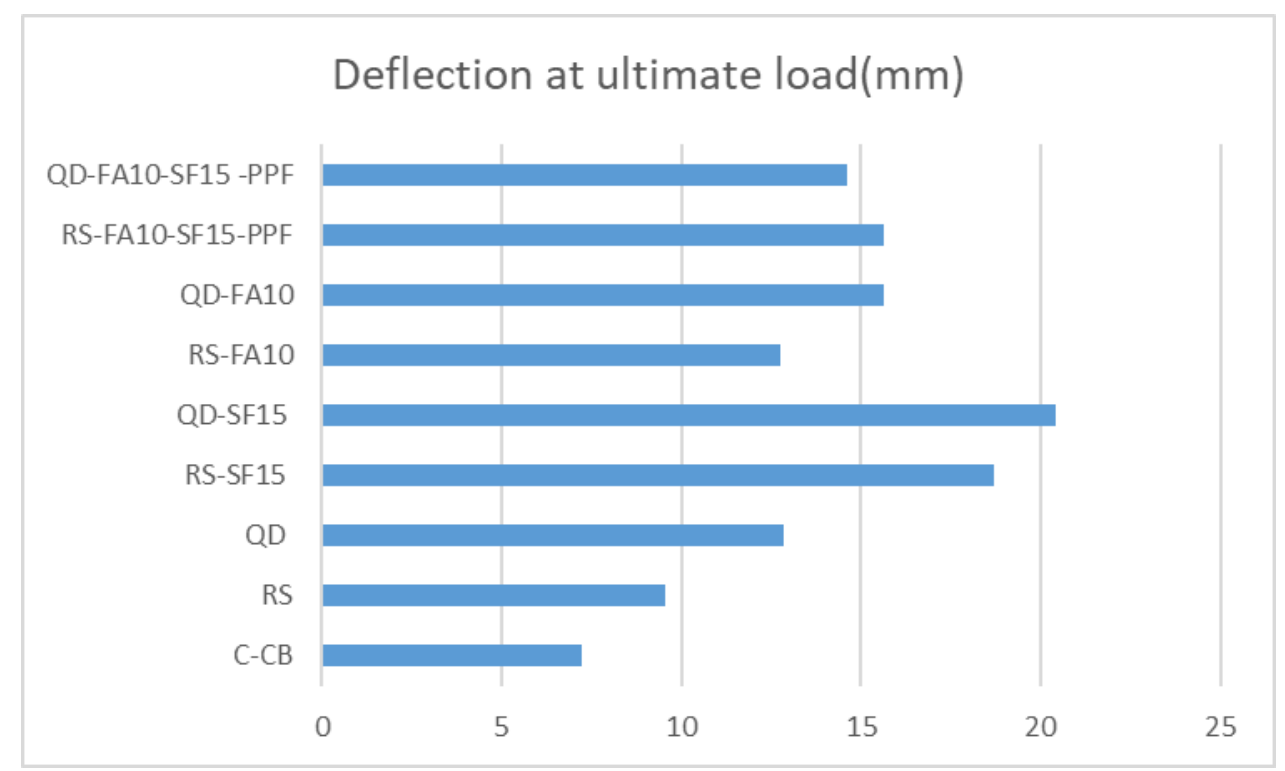

Figure 2. Percentage of increase in yield load of SCC beams in comparison to C-CB beam

\section{Results and Discussion}

In this CFD analysis was used to model experimental-beam behaviour. The model can be generated by prompt input or the interface for a graphical user. The Interface was used to develop the model. In the ANSYS finite element code, the nine beam specimens that were evaluated under four points bending were analyzed. Tables 3.2 define the ultimate experimental and research load and deflection of the final load of the SCC beams.

Table 2. Experimental and Analytical results at Ultimate Load

\begin{tabular}{|c|c|c|c|c|c|}
\hline \multirow{2}{*}{$\begin{array}{l}\text { S. } \\
\text { No }\end{array}$} & \multirow{2}{*}{ Mix code } & \multirow{2}{*}{$\begin{array}{c}\text { Ultimate } \\
\text { Load in } \mathbf{k N}\end{array}$} & \multicolumn{3}{|c|}{ Deflection at Ultimate Load in $\mathrm{mm}$} \\
\hline & & & Experimental & CFD & $\begin{array}{c}\% \\
\text { Error }\end{array}$ \\
\hline 1 & $\mathrm{C}-\mathrm{CB}$ & 89.42 & 7.22 & 6.32 & 7.1568 \\
\hline 2 & $\mathbf{R S}$ & 115.4 & 10.35 & 12.4 & 10.226 \\
\hline 3 & QD & 152.4 & 12.84 & 15.6 & 12.684 \\
\hline 4 & RS-SF15 & 101.3 & 17.83 & 16.2 & 17.668 \\
\hline
\end{tabular}




\begin{tabular}{|l|l|c|c|c|c|}
$\mathbf{5}$ & QD-SF15 & 125.4 & 22.54 & 19.32 & 22.3468 \\
\hline $\mathbf{6}$ & RS-FA10 & 137.33 & 13.64 & 16.38 & 13.4762 \\
\hline $\mathbf{7}$ & QD-FA10 & 152.44 & 15.27 & 15.32 & 15.1168 \\
\hline $\mathbf{8}$ & RS-FA10-SF15-PPF & 162.42 & 19.65 & 19.42 & 19.4558 \\
\hline $\mathbf{9}$ & QD-FA10-SF15 -PPF & 174.31 & 20.4 & 21.4 & 20.186 \\
\hline
\end{tabular}

\subsection{The crack pattern and failure modes of the beams in the CFD model}

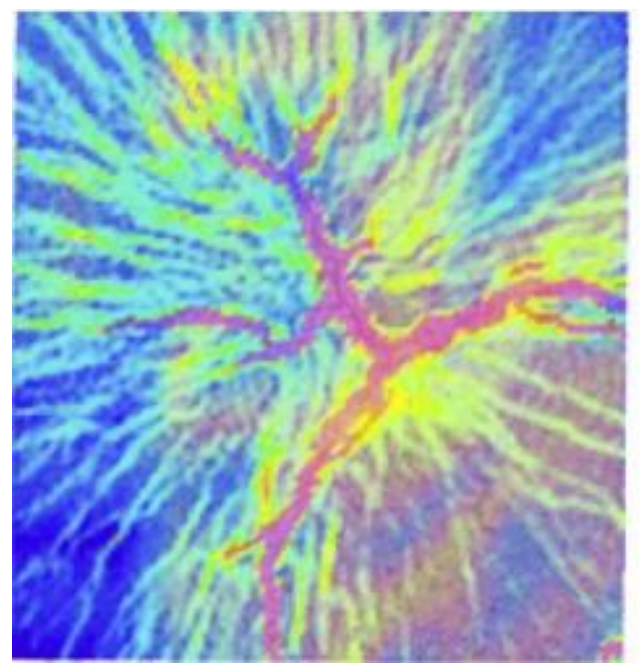

Figure 8. Crack pattern in SCC beam representing QD-FA10-SF15-PPF mix

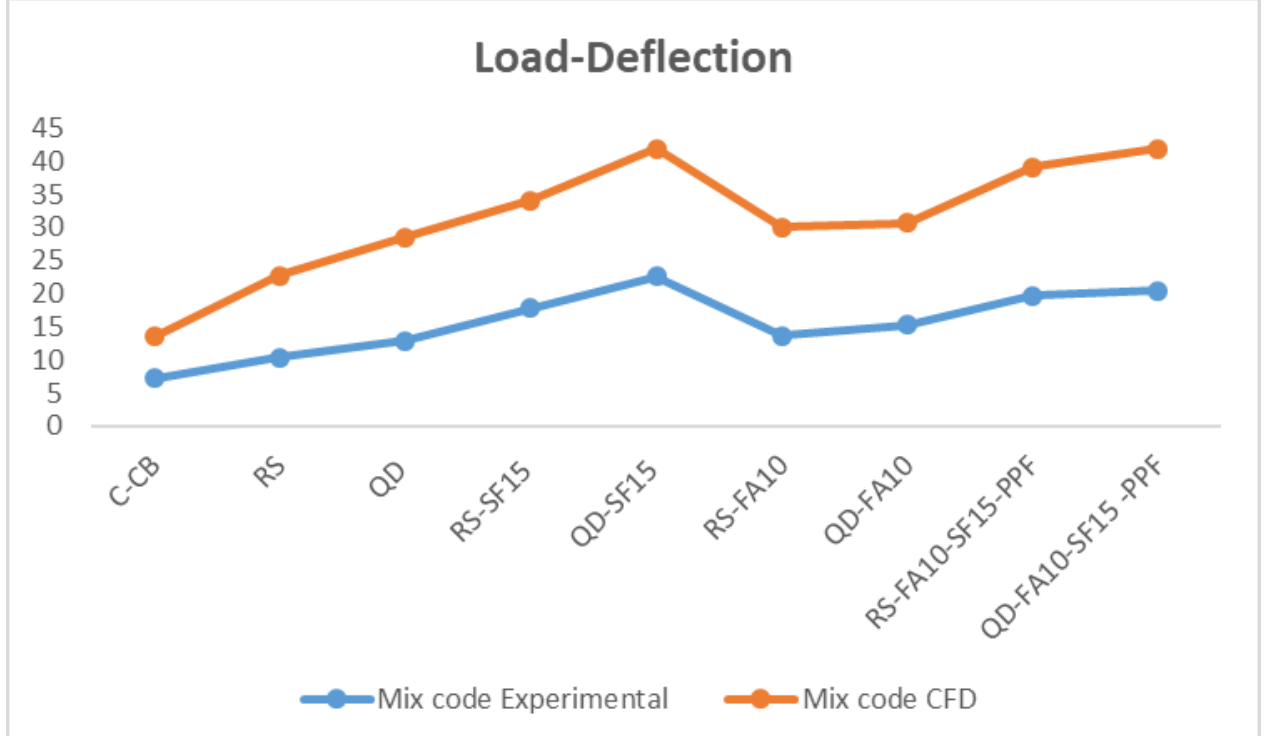

Figure.9. Load-Deflection response of beam representing QD-FA10-SF15-PPF mix

\section{Conclusion}

The results reveal that the experimental and CFD Analysis are reasonably close for all beam categories, indicating that the numerical model used is valid. The method for modelling concrete beams using three-dimensional CFD technique has proven to be a reliable predictive tool for the analysis of concrete beams. However, when performing non-linear CFD, it is 
critical to choose appropriate the correct mesh density to obtain a satisfactory solution to the problem.

\section{References}

1. A. Ghanbari \& B. L. Karihaloo (2009). 'Prediction of the plastic viscosity of self-compacting steel fibre reinforced concrete'. Cement and Concrete Research 39(12):1209-1216.

2. C. K. Aidun \& J. R. Clausen (2010). 'Lattice-Boltzmann Method for Complex Flows'. Annual Review of Fluid Mechanics 42(1):439-472.

3. Y. Yamane, et al. (1994). 'Numerical simulation of semi-dilute suspensions of rodlike particles in shear flow'.Journal of Non-Newtonian Fluid Mechanics 54:405-421

4. OpenFOAM, 2008. The open source CFD toolbox. Users guide.

5. Petersson, O., Hakami, H., 2001. Simulation of self-compacting concrete - laboratory experiments and numerical modelling of testing methods, slump flow, J-ring and L-box tests. In: 2nd International SCC Conference, Tokyo, Japan.

6. Liberato Ferrara, Massimiliano Cremonesi, Marco Faifer, Sergio Toscani, Luca Sorelli, et al.. Structural elements made with highly flowable UHPFRC: Correlating computational fluid dynamics (CFD) predictions and non-destructive survey of fiber dispersion with failure modes. Engineering Structures, Elsevier, 2017, 133, pp.151-171. ff10.1016/j.engstruct.2016.12.026ff. ffhal-01499516

7. Suuronen JP, Kallonen A, Eik M, Puttonen J, Serineaa R, Herrmann H. Analysis of short fibers orientation in steel fiber reinforced concrete (SFRC) by X-ray tomography. J Mater Sci 2013;48:1358-67.

8. Ponikiewski T, Katzer J. X-ray computed tomography of fiber reinforced selfcompacting concrete as a tool of assessing its flexural behavior. Mater Struct 2016. doi: http://dx.doi.org/10.1617/s1527-015-0638y.

9. Orbe A, Losada R, Roji E, Cuadrado J. The prediction of bending strengths in SFRSCC using Computational Fluid Dynamics (CFD). Constr Build Mater 2014;66:587-96

10. Baril MA, Sorelli L, Rethore J, Baby F, Toutlemonde F, Ferrara L, Bernardi S, Fafard M. Effect of Casting Flow Defects on the Crack Propagation in UHPFRC Thin Slabs by Means of Stereovision Digital Image Correlation. Constr Build Mater 2016;129:182-92

11. Ponikiewski T, Katzer J, Bugdol M, Rudzki M. X-ray computed tomography harnessed to determine $3 D$ spacing of steel fibers in self-compacting concrete (SCC) slabs. Constr Build Mater 2015;74:102-8.

12. Van Damme S, Franchois A, De Zutter D, Taerwe L. Nondestructive determination of the steel fiber content in concrete slabs with an open ended coaxial probe. IEEE Trans Geosci Remote Sens 2009;42(11):2511-21 